\title{
Simultaneous trabeculectomy and cataract extraction
}

\author{
MIRIAM ROMEM, IZCHAK ISAKOW, AND ZVI DOLEV \\ From the Department of Ophthalmology, the Edith Wolfson Hospital, Holon, the Sackler School of \\ Medicine, Tel-Aviv University, Israel
}

SUMMARY A combined trabeculectomy and cataract extraction was performed on 46 eyes of 39 patients. The average follow-up period was of 27 months. The intraocular pressure remained controlled without the need of postoperative medication in 33 eyes $(71.74 \%) ; 12$ eyes $(26.09 \%)$ needed further medical treatment; and in one eye the pressure remained uncontrolled and further surgery was necessary. After surgery the visual acuity improved considerably and the complications were few. The combined procedure has many advantages. The patient is cured by one surgical procedure, his visual acuity improves, his intraocular pressure is reduced to normal, and he is relieved from the need for medication postoperatively. By a single stay in hospital and by reducing the number of postoperative medical routine controls the expenses are reduced considerably. Owing to these advantages the combined procedure deserves to be considered in cases of glaucoma and cataract.

Opinions on the treatment of a cataract in an elderly patient with glaucoma differ from one author to another. According to some authors the cataract extraction alone makes the intraocular pressure (IOP) normal.' Others believe that the cataract extraction alone renders the control of glaucoma more difficult ${ }^{2}$ and the lens extraction seldom relieves a coexisting glaucoma. ${ }^{3}$ Different combined surgical methods have been recommended, ${ }^{4-7}$ and when trabeculectomy took over the leading role $^{8}$ European, ${ }^{9-11}$ Japanese,$^{12}$ and American surgeons ${ }^{213}$ recommended a combined trabeculectomy and cataract extraction.

From 1977 to 1980 a combined trabeculectomy and cataract extraction was performed in our department on 46 eyes. The present study discusses the results, indications, and advantages of this procedure.

\section{Material and methods}

Since 1977, 46 eyes of 39 patients have undergone a combined trabeculectomy and cataract extraction. The age, sex, and follow-up period, the preoperative recordings, the indications, the results of measuring the intraocular pressure (IOP) and visual acuity, and the complications are shown in Tables 1, 2, 3, 4, 5, 6, and 7 respectively.

Correspondence to Dr M. Romem. Department of Ophthalmology, Edith Wolfson Hospital. Holon, Israel.
Surgical method. A limbus-based conjunctival flap, a scleral $3 \times 4 \mathrm{~mm}$ trapdoor flap, trabeculectomy and peripheral iridectomy, enlargement of the corneoscleral incision, lens extraction by cryosurgery, suturing of the wound by $8-0$ virgin silk sutures, and instillation of $1 \%$ atropine drops were carried out.

Patients. The main age group was between the 7 th and 8th decade, the follow-up 12-42 months, average 27 months (Table 1). The preoperative findings are

Table 1 Age, sex, and follow-up period (46 eyes of 39 patients)

\begin{tabular}{llllll}
\hline Age: & $50-60 \mathrm{yr}$ & $60-70 \mathrm{vr}$ & $70-80 \mathrm{yr}$ & Over 80 vr & Total \\
\hline No.: & 3 & 7 & 27 & 9 & 46 \\
\hline Sex: & 29 Females & 17 Males & & \\
\hline Follow-up period: $12-42$ & months, average 27 months
\end{tabular}

shown in Table 2. Thirty-eight patients had open- and 8 had narrow-angle glaucoma. Glaucomatous excavation was present in 22 eyes; the fundus was normal in 13 eyes; and because of a fixed miotic pupil the fundus findings were invisible in 11 eyes. Visual field defects were found in 14 eyes; 4 of them had tubular fields. The visual fields were normal in 8 and unknown in 24 eyes. 
Table 2 Preoperative recordings

\begin{tabular}{lc}
\hline & No. of eves \\
\hline $\begin{array}{l}\text { Kind of glaucoma } \\
\text { Open angle }\end{array}$ & 38 \\
Narrow angle & 8 \\
\hline Fundus & 22 \\
Glaucomatous excavation & 13 \\
No excavation & 11 \\
Unvisible & \\
\hline Visual fields & 14 \\
Defects & 8 \\
Normal & 24 \\
Unknown & \\
\hline OOP & 0 \\
Controlled without medication & 22 \\
Controlled by medication & 24 \\
Uncontrolled & \\
\hline
\end{tabular}

Treatment. All the patients received antiglaucomatous treatment preoperatively. 'Maximal medication' means frequent and various kinds of topical and systemic antiglaucomatous medication.

The IOP was controlled by medication in 22 eyes and uncontrolled in 24 preoperatively. By 'controlled' we mean an intraocular pressure below $21 \mathrm{mmHg}$ at all times round the clock. By 'uncontrolled' we mean an intraocular pressure over $24 \mathrm{mmHg}$, significant diurnal variations, and evidence of a damaging effect of the increased pressure on the eye.

The indications for a combined procedure (Table 3 ) were uncontrolled glaucoma and cataract in 24 eyes and controlled glaucoma and cataract in 22 eyes. In the uncontrolled glaucoma group the IOP was over 24 $\mathrm{mmHg}$, with significant diurnal variations. The controlled glaucoma group included patients with increasing visual field defects (8 eyes), aphakia and

Table 3 Indications for a combined procedure

\begin{tabular}{lll}
\hline & No. of eves \\
\hline 1. & Uncontrolled glaucoma and cataract & 24 \\
2. & Controlled glaucoma and increasing visual & \\
& field defect & 8 \\
3. & Aphakia and glaucoma in the fellow eye & 4 \\
4. & Glaucoma surgery in the fellow eye & 8 \\
5. & Controlled glaucoma central cataract and & 17 \\
& maximal miosis & 17 \\
\hline
\end{tabular}

Table 4 Postoperative IOP

\begin{tabular}{lcc}
\hline & No. of eves & Percentage \\
\hline Controlled without medication & 33 & $71 \cdot 74$ \\
Controlled by medication & 12 & $26 \cdot 09$ \\
Uncontrolled & 1 & $2 \cdot 17$ \\
Total & 46 & 100 \\
\hline
\end{tabular}

glaucoma, or glaucoma surgery, in the fellow eye (4 and 8 respectively). In 17 eyes a central cataract and maximal miosis handicapped the patient.

Forty-three eyes had an intracapsular and 3 eyes an extracapsular lens extraction (one planned and 2 unplanned extracapsular extractions). The lens was extracted through a round pupil in 29 eyes; in 17 eyes an iridotomy was necessary in order to facilitate the extraction. In 17 eyes a synechiolysis was performed, and 2 eyes had vitreous loss.

\section{Results}

The results of operation are shown in Table 4, and compared with the preoperative readings in Table 5.

Table 5 Comparison between the preoperative and postoperative IOP results

\begin{tabular}{lcc}
\hline & \multicolumn{2}{c}{ No. of eves and percentage } \\
\cline { 2 - 3 } & Preoperative & Postoperative \\
\hline Controlled without medication & 0 & $33(71 \cdot 74 \%)$ \\
Controlled by medication & $22(47 \cdot 8 \%)$ & $12(26 \cdot 09 \%)$ \\
Uncontrolled & $24(52 \cdot 2 \%)$ & $1(2 \cdot 17 \%)$ \\
Total & $46(100 \%)$ & $46(100 \%)$ \\
\hline
\end{tabular}

Table 6 Visual results

\begin{tabular}{lllll}
\hline $6 / 6-6 / 10$ & $6 / 15-6 / 20$ & $6 / 30-6 / 60$ & Less than 6/60 & Total \\
\hline 16 & 17 & 6 & 7 & 46 \\
\hline
\end{tabular}

Table 7 Postoperative complications

\begin{tabular}{llll}
\hline Early & No. of eves & Late & No. of eves \\
\hline $\begin{array}{l}\text { Hyphaema } \\
\text { Shallow anterior } \\
\text { chamber }\end{array}$ & 4 & $\begin{array}{l}\text { Post. synechiae } \\
\text { Lens residua }\end{array}$ & 5 \\
$\begin{array}{c}\text { Choroid } \\
\text { detachment }\end{array}$ & 3 & $\begin{array}{c}\text { haemorrhage } \\
\text { Staphyloma }\end{array}$ & 1 \\
$\begin{array}{c}\text { Vitreous } \\
\text { haemorrhage }\end{array}$ & 2 & 1 \\
\hline
\end{tabular}

Thirty-three eyes had a controlled IOP without the need of medication, 12 eyes needed medication postoperatively, and in one eye the pressure remained high and further surgery was necessary.

A visual acuity (Table 6) of 6/6-6/10 was achieved in 16 eyes, $6 / 15-6 / 20$ in 17 eyes, $6 / 30-6 / 60$ in 6 eyes, and less than $6 / 60$ in 7 eyes. There was complete atrophic glaucomatous excavation in 2 eyes, severe macular degeneration in 3 eyes, vitreous haemorrhage in one eye, and lens residua in one eye. These were the results following one surgical procedure.

The complications are shown in Table 7 . The early 
complications were hyphaema (4 eyes), shallow anterior chamber ( 3 eyes), choroidal detachment ( 3 eyes), and vitreous haemorrhage ( 2 eyes). The late complications were posterior synechiae ( 5 eyes), lens residua (one eye), vitreous haemorrhage (one eye). An unusual complication developed in one eye: the IOP remained uncontrolled and a staphyloma developed at the corneoscleral section in the upper nasal quadrant. The patient underwent further surgery and the IOP became normal, but the visual result was poor owing to complete glaucomatous excavation.

\section{Discussion}

The combined operation of trabeculectomy and cataract extraction is not a popular procedure for several reasons. Some believe that the lens extraction alone can control the postoperative IOP, ${ }^{1}$ that the control of the IOP is of a temporary character, ${ }^{14}$ or that the combined procedure carries a high surgical risk $^{13}$ and severe complications. ${ }^{15}$

In all our patients except one the IOP remained controlled over a long period of time; 33 eyes did not need medication postoperatively $(71.74 \%)$. As Witmer $^{3}$ stated, the extraction of cataract seldom relieves a coexisting glaucoma, and all eyes with this disorder need medical treatment. When an aphakic glaucoma develops, it is difficult to manage, the uncontrolled IOP is followed by a deterioration of the ocular function, and therefore even heroic measures have been suggested. ${ }^{16}$ The complications in our cases were few and of a temporary character, and in our opinion, as in the opinion of others, ${ }^{13}$ the combined procedure is no more traumatic than an ordinary cataract extraction.

Most of our patients were in the 7th and 8th decades, and most of them enjoyed good results from this procedure. Their visual acuity improved considerably, their IOP became normal, and only a few needed medication. In addition most of them feel a relief from routine administration of drops and routine and repeated medical control. The advantages of this procedure are not only medical but also financial: a single operation cuts the expenses considerably. Because of good visual results, the long-lasting control of the IOP, and the few complications the combined procedure is to be considered in patients with glaucoma and cataract.

\section{References}

1 Randolph ME. Maumenee AE. Ilif CE. Cataract extraction in glaucomatous eyes. Am J Ophthalmol 1971: 71: 328-30.

2 Johns GE. Layden WE. Trabeculectomy combined with cataract extraction. Am J Ophthalmol 1979; 88: 973-81.

3 Witmer R. Kombinierte Glaucom-Katarakt-Operation. Ophthalmologica 1972; 165: 203-7.

4 Birge HL. Glaucoma with cataract surgically cured with a single operation. Trans Am Ophthalmol Soc 1952: 50: 241-63.

5 Hughes WL. Report on a combination operation for cataract with glaucoma. Am J Ophthalmol 1959: 48: 1-14.

6 Hauer I. Simultaneous cataract glaucoma. Isr Med J 1960): 19: 254-6.

7 Galin MA. Baras I. Sambursky J. Glaucoma and cataract. A study of cyclodialysis-lens extraction. Am J Ophthalmol 1969: 67: $522-6$.

8 Cairns JE. Trabeculectomy. Am J Ophthalmol 1968; 66: 673-9.

9 Eustace P. Harum AOSM. Trabeculectomy combined with cataract extraction. Trans Ophthalmol Soc UK 1974: 94: 1058-63.

10 Bregeat P. Combined cataract surgery and trabeculectomy. Klin Monatsbl Augenheilkd 1975: 167: 505-15.

11 Witmer R. Rohen JW. Combined cataract-glaucoma operation. Trans Ophthalmol Soc UK 1976; 96: 256-61.

12 Kuroda J. Takatsuki R. Yoshimura T. et al. Cataract combined with trabeculectomy. Jpn J Clin Ophthalmol 1978: 32: 103-8.

13 Jerndal $T$. Lundstrom $M$. Trabeculectomy combined with cataract extraction. Am J Ophthalmol 1976; 81: 227-31.

14 Maumenee AE. In: McPherson SD. Combined trabeculotomy. and cataract extraction as a single operation. Trans Am Ophthalmol Soc 1976: 74: 250-60.

15 Lowe RF. Shallow AC after combined trabeculectomy-cataract extraction. Aust J Ophthalmol 1977: 5: 180-2.

16 Lee PF. Argon laser photocoagulation of ciliary process in cases of aphakic glaucoma. Arch Ophthalmol 1979: 97: 2135-8. 